\title{
Reconhecimento e consenso na antropologia e na ética filosófica de Lima Vaz
}

\author{
Recognition and consensus \\ in the anthropology and \\ philosophical ethics of Lima Vaz
}

\author{
João Elton de Jesus \\ Universidade Católica de Pernambuco (UNICAP) \\ Orcid 0000-0001-5339-3870 \\ joao.elt@gmail.com
}

Resumo: Este trabalho tem o objetivo de apresentar as categorias de Consenso e Reconhecimento na obra de Henrique Cláudio de Lima Vaz SJ. Mostraremos que, embora esse filósofo brasileiro enfatize tais conceitos na obra Introdução à Ética Filosófica II, tais categorias já estavam presentes de forma seminal em seu livro Antropologia Filosófica II. Verificaremos a importância de ambos conceitos para a construção de uma ética que garanta a subjetividade e esteja em consonância com a comunidade. Primeiramente, apresentaremos as bases antropológicas do pensamento desse filósofo jesuíta; em seguida, verificaremos o que ele chama de agir e vida ética e, finalmente, debruçaremos sobre Reconhecimento e Consenso como condição de possibilidade para o agir do ser humano em harmonia com os outros e com o seu contexto.

Palavras-Chave: Antropologia; Ética; Lima Vaz; Reconhecimento; Consenso. 
Abstract: This work aims to show the categories of consensus and recognition in the work of Henrique Cláudio de Lima Vaz. We show, that although this Brazilian philosopher emphasizes such concepts in the work Introdução à Ética Filosófica II (Introduction to Philosophical Ethics II), such categories were already present in seminal form in his book Antropologia Filosófica II (Philosophical Anthropology II). We will verify the importance of both concepts to the construction of an ethics that ensures the subjectivity and is in line with the community. First, we will present the anthropological bases of the thought of this Jesuit philosopher; then, we will verify what he calls acting and ethical life and, finally, we will look at Recognition and Consensus as a condition of possibility for human beings to act in harmony with others and with their context.

Keywords: Anthropology; Ethic; Lima Vaz; Recognition; Consensus.

O religioso jesuíta Henrique Claudio de Lima Vaz, SJ (1921 - 2002), é considerado um dos grandes nomes da filosofia do Brasil do século XX. Lima Vaz interpreta a filosofia como uma forma de vida. Ele a pensa a partir das dificuldades dos problemas com os quais se confronta na realidade. Para ele, não havia dissociação da experiência vivida e da filosofia, ou seja, a filosofia deve se desenvolver a partir dos desafios e questionamentos da vida e da existência humana. Para Mcdowel (2011, p.233) "[...] é igualmente decisivo o seu compromisso com a realidade atual, mundo humano, mundo moderno, do qual se sente plenamente cidadão e que pretende compreender e servir com sua investigação".

Filho de professor e fortemente influenciado por Platão, Hegel e Santo Tomás de Aquino, Lima Vaz é "considerado um dos mais significativos representantes do pensamento humanista contemporâneo no Brasil, desenvolve seu pensamento filosófico em contato com a tradição filosófica e em diálogo constante com a atualidade". (SANTOS, 2013, p.5). Interrogado pelas grandes questões de seu tempo e privilegiado pela formação recebida na Companhia de Jesus, esse pensador traçou o seu pensamento em três grandes linhas, que formam em si uma grande unidade: a Antropologia, a Ética e a Metafísica. 
Ao buscar entender a natureza e o sentido do ser humano e como este deve agir, Lima Vaz desenvolveu, paralelamente, uma antropologia filosófica e uma ética filosófica, em que sistematiza e organiza algumas respostas para o niilismo moderno e um "equilíbrio" entre as novidades apresentadas pela contracultura e o saber tecnocientífico, que, segundo ele, trata-se de um "resíduo anacrônico da civilização que termina, [...] pretende retirar qualquer valor ao problema ético e confiar a conduta da vida humana a técnicas controláveis de comportamento e previsão". (LIMA VAZ, 2000, p. 241)

Tendo em vista a importância que esse autor dá à ética e à antropologia e levando em consideração a importância do outro para a constituição de uma sociedade harmoniosa, ainda que em um contexto de conflito, buscaremos, nesse artigo, identificar como Lima Vaz trabalha a categoria de Reconhecimento e Consenso em sua obra. Já apresentamos de antemão que esses conceitos, que são mais evidentes na sua ética, já estavam presentes na sua antropologia, de modo que, então, buscaremos nos debruçar nesses dois arcabouços a fim de verificar tais categorias.

Nesse sentido, buscaremos, primeiramente, apresentar a antropologia vaziana, que ao lado da metafísica, forma a base para aquilo que o autor chama de ética. Em seguida, nos debruçaremos sobre o agir e a vida ética propugnado por Lima Vaz, de modo, assim, a ter os fundamentos necessários para, enfim, apresentarmos e melhor compreendermos os conceitos de Reconhecimento e Consenso propostos por esse pensador brasileiro.

\section{A Antropologia Ética de Lima Vaz}

Diante de uma modernidade ou pós-modernidade pautadas pelas ciências e por diversos saberes que buscam a sua "verdade" sobre a realidade, Henrique de Lima Vaz não leva em consideração um ser humano fragmentado, desraigado da sua condição antropológica ou mesmo da sua plenificação enquanto um ser de ação. Segundo esse filósofo, a interrogação fundamental "o que é o homem?", permeia as mais diversas expressões da cultura como o mito, literatura, ciência, filosofia, 
ethos e política, nisso "emerge com fulgurante evidencia essa singularidade própria do homem que é a de ser o interrogador de si mesmo, interiorizando reflexivamente a relação sujeito-objeto por meio da qual ele se abre ao mundo exterior". (LIMA VAZ, 1991, p. 09)

No pensamento de Vaz, a visão de homem no mundo ocidental dá origem a duas formas do saber humano: a metafísica e a ética. "A Antropologia filosófica deve situar-se na interseção desses dois saberes, na medida em que ela irá coroar sua explicação do homem com as duas prerrogativas da "razão teorética" e da "razão prática". (VAZ, 1991, p.157). Ao observar o seu contexto, Lima Vaz constata que a abordagem cientificista do homem é redutora e limitada, pois foca somente aquilo que pode ser objetivado. Segundo ele, no século $\mathrm{XX}$, duas tendências ou correntes tentaram superar a crise que envolve o entendimento do homem dentro do mundo ocidental: o naturalismo, que professa um reducionismo mais ou menos estrito do fenômeno humano à natureza material como fonte última de explicação (...) e o culturalismo, que acentua a originalidade da cultura em face da natureza, separando no homem o "ser natural" e o "ser cultural". (VAZ, 1991, p. 10)

Tendo em vista a sua formação filosófico-teológica, Lima Vaz busca resgatar o aspecto transcendente do homem. O autor afirma que "no espírito finito e, portanto, no homem, a abertura e inclinação para o Verdadeiro e o Bem são transcendentais porque constitutivas de sua essência" (VAZ, 1991, p. 233). Desta forma, a antropologia filosófica de Lima Vaz busca uma ponte entre o mundo das ciências e o mundo transcendente e assim chegar a uma compreensão que contemple a totalidade do homem.

No pensamento antropológico vaziano, a pergunta norteadora sobre o que é o homem, pode, então, ser respondida primeiramente por meio de categorias que ele chama "estruturais" das quais apresentamos abaixo, ainda que de forma objetiva, dada a amplitude de tais conceitos.

A categoria estrutural de corpo próprio revela uma "dimensão constitutiva e expressiva do ser do homem" (LIMA 
VAZ, 1992, p.157) de modo que é pelo corpo próprio do sujeito (Eu) que o ser humano se expressa e se faz presença no mundo. Assim o homem é corpo, pois sem sua corporalidade própria estaria incapacitado de realizar ações humanas como falar, sentir, trabalhar, pensar etc. Contudo, para Vaz, "o homem não é o (seu) corpo [...], ao suprassumir o corpo-objeto no corpo-próprio o sujeito afirma o seu ser como transcendendo os limites da corporalidade, ou seja, os limites da presença imediata do homem no mundo". (VAZ,1991, p. 182). Nesse sentido, como sujeito, o homem suprassume o corpo-objeto em um corpo-próprio, cheio de intencionalidade, que transcende os limites da corporalidade objetiva mostrando, pois, que, além do corpo objetivo e próprio, há outros elementos.

A Categoria de Psiquismo revela que, além de corpo, o homem também é interioridade, pois traz consigo um "mundo interior que está ligado a um espaço-tempo que obedece ao ritmo de percepções, representações, memória, emoções e pulsões" (OLIVEIRA, 2013, p. 175). Este aparece como um mediador entre a presença imediata do homem em seu corpo próprio e a interioridade absoluta pelo espírito, pois, tal como afirma Lima Vaz (1991, p.94),

O psíquico se apresenta, pois, como domínio de uma presença mediata do homem no mundo e como primeiro momento da presença do homem a si mesmo, presença essa mediatizada pelo mundo interior do próprio psiquismo. Podemos dizer, portanto, que estruturalmente o psiquismo e o sujeito exprimindo-se na forma de um Eu psicológico, unificador de vivencias, estados e comportamentos.

No entanto, o psíquico (interno) em oposição ao somático (externo) revela ainda uma impossibilidade da categoria de psiquismo de dar a resposta sobre o que é o homem, sendo necessário, portanto, ir "para além das fronteiras do somático e do psíquico: num último passo dialético na constituição das estruturas do ser-homem" (LIMA VAZ, 1991, p. 195).

Por fim, dentro das categorias estruturais, situa-se aquela chamada de espírito, pois para Lima Vaz (1991, p.201) com essa categoria "atingimos o ápice da unidade do ser humano. É nesse nível que o ser do homem abre-se necessariamente 
para a transcendência: trata-se de uma abertura propriamente transcendental, [...] um ser estruturalmente aberto para o Outro". Nesse sentido, Lima Vaz (1991, p.222) argumenta que a afirmação "o homem é espírito significa, pois, a abertura transcendental do homem à universalidade do Ser segundo o duplo movimento do acolhimento e do dom, da razão e da liberdade", nesse mesmo sentido segue o pensamento de Oliveira (2013, p.176) ao afirmar que a partir dessa categoria, mas pressupondo o corpo e a psique, a pessoa humana "se experimenta como inteligência e liberdade. Enquanto inteligência, ele se constitui como abertura ilimitada à Verdade. Enquanto liberdade, ele se inclina ao Bem" (OLIVEIRA, 2013, p. 176).

Em sua antropologia filosófica, Lima Vaz percebe que somente as categorias estruturais não são suficientes para abarcar a complexidade do ser humano, pois ao afirmar-se "Eu sou', o homem, aberto para o outro, faz também a experiência do seu ser-em-relação com o mundo, com relação aos demais e com relação ao Outro Absoluto" (OLIVEIRA, 2013, p. 176). Nesse sentido, o filósofo brasileiro insere em sua antropologia as categorias relacionais: objetividade, intersubjetividade e transcendência.

A categoria de objetividade apresenta a relação do ser humano com o mundo. Trata-se de uma atitude ativa do homem diante do mundo, que faz a experiência de ser "finito e situado" (LIMA VAZ,1992, p.29). Assim, o homem inserido na história, na cultura, no tempo e no espaço, age no mundo por meio da ciência e da técnica, por meio da produção e da linguagem. No entanto, através dessa mesma linguagem, é possível verificar que o ser humano está em relação com o outro. Dessa maneira, a categoria de objetividade é supraassumida por uma dimensão ou outra categoria relacional que Lima Vaz chama de intersubjetividade, "A suprassunção significa aqui que a forma do ser-no-mundo como autoexpressão do sujeito implica necessariamente a forma do ser-com-o-outro que é, justamente, a forma da relação intersubjetiva" (LIMA VAZ, 1992, p. 55). Desta maneira, inserido no mundo de forma objetiva por meio de suas ações e linguagem que se comunica com outros, Vaz pressupõe o reconhecimento do outro (que explanaremos melhor a seguir), de modo a podermos dizer que o ser humano 
é também intersubjetivo, um ser-para-o-outro, tem um existir-em-comum. Nesse sentido, esse pensador afirma o seguinte:

Com efeito, o indivíduo humano monadicamente isolado em qualquer das manifestações de sua existência é uma abstração. Em sua gênese e desenvolvimento ele está envolvido numa rede de relações, desde as relações elementares com a Natureza até as relações propriamente inter-humanas que definem as condições de possibilidade de sua autoafirmação como Eu. Um Eu que é, portanto, indissoluvelmente um Nós. (LIMA VAZ, 2000, p.67)

Todavia, o filósofo jesuíta avança em sua reflexão e afirma que a totalidade estrutural do sujeito é experimentada como um ser espiritual. Para ele há uma dimensão relacional constitutiva do ser humano denominada como categoria da transcendência onde se "caracteriza pela relação entre a finitude intencional do sujeito e a infinitude real do Absoluto. Nesse sentido, o homem percebe-se como um ser-para-o-Absoluto onde "o sujeito finito e situado se eleva à infinitude do ser, da Verdade e do Bem" (OLIVEIRA, 2013, p.184).

A relação de transcendência exprime como que o excesso ontológico (do sujeito enquanto se auto-afirma como ser), pelo qual nos sobrepomos ao mundo e à história (o que é evidente quando refletimos sobre o mundo e a história no horizonte do ser) e avançamos, assim, além do ser-no-mundo e do ser-com-o-outro, buscando um fundamento último para o Eu sou primordial que o constitui. (LIMA VAZ, 1997, p. 195)

Em suma, podemos afirmar, então, que o ser humano é corpo, psique e espirito e sendo um ser de relações, se percebe na sua relação objetiva com o mundo, na relação intersubjetiva com os outros e na relação de transcendência com o Absoluto. A unidade desses aspectos do ser humano, do ser-para-si e do ser-para-outros, acontece através da categoria de realização que se constitui na "efetivação existencial do paradoxo segundo o qual o homem se torna ele mesmo (ipse) na sua abertura constitutiva ao outro" (VAZ, 1992, p.145). Isso é confirmado esclarecido por Oliveira (2013, p.186) quando afirma que "no momento da realização, a existência se efetiva como operação. O homem é, pois, necessariamente existência em ato (enérgeia). Enquanto ato, ele se constitui com progressivo mo- 
vimento em direção à conquista de sua unidade existencial, ou seja, de sua perfeição".

Nesse arcabouço antropológico construído por Lima Vaz emerge a categoria de pessoa, que aparece como uma síntese da essência (o ser que é) e da existência (o ser que se torna ele mesmo) do ser humano. Pois segundo Lima Vaz (2000, p. 190) "a categoria de pessoa se apresenta, tanto na sua procedência histórica como nas suas exigências teóricas, como a mais apta a exprimir toda a riqueza inteligível que se adensa nesse estágio, o mais elevado, da auto-afirmação do sujeito". Essa unidade final do homem, não é um novo conteúdo, mas um método, um caminho que conduz a expressão acabada do Eu Sou. Trata-se, portanto, de uma dinâmica, de uma contínua tarefa de realizar-se na mais radical humanidade, ainda que, dada a dimensão finita, o homem nunca atingirá plenamente o seu ser.

Lima Vaz parte do pressuposto de que a pessoa humana enquanto aberta à Verdade e ao Bem é constitutivamente um ser moral. Segundo esse autor, na experiência da pessoa e em relação com os outros "se descobre a orientação profunda do movimento de auto-realização do homem e o dinamismo original do existir no operar - operari sequitur esse - que é, no homem, a passagem propriamente humana da essência na existência, o cumprir-se do "torna-te aquilo que és" (LIMA VAZ, 2000, p. 210).

Em sua Introdução a Ética Filosófica II, Lima Vaz (2000, p.237) afirma que "a pessoa é constitutivamente ética e o predicado da eticidade se estende a todas as suas manifestações: psicológica, social, política, jurídica, profissional e outras". Nesse sentido, a categoria de pessoa afirmada na antropologia, propugnada por ele, traz inerentemente a ética consigo. O ser humano só é pessoa se busca um agir e uma vida ética. Por isso, então, que dados os pressupostos da antropologia, Lima Vaz se debruça na ética a fim de buscar as normas e os fins que possibilitam a realização humana, a nossa realização como pessoa. Nesse sentido, a pessoa moral é considerada como o próprio ser em constante movimento em direção à sua realização, assim, é aquele ser humano capaz de viver uma vida ética. Portanto, 
Lima Vaz busca compreender como se dá a vida ética, o que apresenta na parte sistemática de sua Ética Filosófica, onde foca o agir e a vida ética.

\section{$O$ agir e a vida na ética de Lima Vaz}

Nas obras de Introdução à Ética Filosófica, Lima Vaz faz uma abordagem histórica (volume 1) e sistemática (volume 2) da ética. Nesta última, o filósofo brasileiro divide o conteúdo em duas partes, o agir e a vida ética. Focaremos em nosso trabalho os capítulos que abordam o aspecto intersubjetivo de ambos, onde abordaremos a questão do Consenso e do Reconhecimento. Contudo, antes disso, faremos uma breve explanação sobre alguns pressupostos da ética vaziana.

Tal como vimos acima, o ser humano faz da sua vida uma continua busca de um existir pleno que ocorre a partir de uma vida ética. Nesse sentido, toda ação humana traz intrinsicamente uma ação ética, um agir ético. Esse agir ético remonta ao ser humano a seguinte pergunta já trazida por Sócrates que se perguntava “como convém viver'. Lima Vaz por sua vez, fiel à filosofia e à sua concepção de homem, propõe, tal como afirma Herrero (2012, p. 397), "o modelo de vida segundo a razão ou de vida sensata é capaz de justificar-se como tal". Desta maneira, o agir ético daquele que diz "Eu sou" é um agir ético racional e a forma mais adequada para essa empresa é a razão prática, que assim como o ethos, é universal. Segundo Lima Vaz (1999, p. 39),

O ethos é a morada do animal e passa a ser a casa (oikos) do ser humano, não já a casa material que lhe proporciona fisicamente abrigo e proteção, mas a casa simbólica que o acolhe espiritualmente e da qual irradia para a própria casa material uma significação propriamente humana, entretecida por relações afetivas, éticas e mesmo estéticas, que ultrapassam suas finalidades puramente utilitárias e a integram plenamente no plano humano da cultura".

Para melhor ilustrar a razão prática, faremos uso de Oliveira et. Cardoso (2008, p.407) que dizem que na diferenciação aristotélica dos saberes, teórico, prático e poiético "a razão prática busca o saber para alcançar, através dele, a perfei- 
ção moral (...)o saber prático tem como escopo a perfeição do agente que cumpre a ação". Já para Ribeiro (2015, p.157) "A Razão é aqui entendida como racionalidade prática ou razoabilidade e encontra uma expressão concreta na figura do sábio, exemplo por excelência de figura ética que aparece nos mais variados perfis em praticamente todas as tradições culturais".

Tendo em vista que o homem é um ser espiritual ou de razão e vontade, para Lima Vaz, em sua universalidade, o agir ético do sujeito, o seu ato moral, tem uma racionalidade implícita, uma razão prática que se exprime através de princípios de natureza teleológico-normativa em que prescreve o Bem como telos de toda ação do homem. Segundo Oliveira (2013, p.212), "aberta pela vontade ao Bem, ela inclina o sujeito a aderir ao melhor em vista da realização".

Para Lima Vaz, essa tendência instintiva do homem de praticar o bem, a conaturalidade da inteligência e da liberdade do homem com a Verdade e o Bem, é alimentada por aquilo que o filósofo brasileiro chama de hábito ou especificamente de sindérese, que ele entende como "sinergia do conhecimento e da inclinação tendo por objeto o bem" (LIMA VAZ, 2000, p. 60). Esse hábito, ou seja, esse ato ético, se realiza no decorrer da vida em um processo que leva o ser humano a sua plenitude cuja constância da prática de ações orientadas pelo bem, conduz o homem a ser cada vez mais virtuoso. Em outras palavras, a sindérese vai se aplicando continuamente na vida e tornando o ser humano um sujeito ético, ou seja, um "sujeito agente possuidor de virtude". (OLIVEIRA, 2013, p.212)

É interessante ressaltar que esse processo instaurado na vida ética é caracterizado por uma dialética entre o estático, onde o sujeito já é bom e virtuoso; e o dinâmico, pois esse mesmo sujeito ético está em constante movimento de crescimento em direção ao Bem, assumindo cada vez mais hábitos virtuosos, de modo que a sua bondade pode continuamente se tornar melhor. Por isso que Oliveira (2013) comenta que, para Vaz, a vida ética é um contínuo e progressivo movimento em direção ao Bem, ainda que um Bem absoluto nunca seja alcançado em sua plenitude, pois, segundo esse autor, a estrutura corporal 
e psíquica da pessoa além de interferências cultuais e sociais, fazem dela um ser limitado e finito. Assim essa identidade só acontece de forma intencional, uma identidade na diferença que faz com que a virtude seja sempre, ao mesmo tempo, o conquistado e o ainda a ser conquistado.

Diante desses fatores condicionantes que impede a identidade total com a verdade e o Bem, a razão prática deve buscar então deliberar e agir. Nesse processo, a racionalidade do agir denominada como phronesis orientará o sujeito agente nesse processo de escolha, visando, em meio a esses fatores, conduzir o sujeito para ação mais virtuosa. Nesse sentido a phronesis se caracteriza como capacidade de escolha e o livre-arbítrio se constituirá como "mediadora essencial entre a universalidade dos princípios e a singularidade da ação" (LIMA VAZ, 2000, p. 49), de modo que esse sujeito sempre busque aquilo que o leve para a uma vida mais virtuosa, para o melhor.

Dessa maneira, podemos dizer que a ação prática se efetiva concretamente na ação singular, ou seja, no ato moral, pois é no momento da ação do indivíduo, que a razão prática exerce uma reflexão sobre o próprio ato, avaliando a conformidade de tal ação à luz da norma do Bem. Essa reflexão e juízo da ação é denominada por Lima Vaz como consciência moral que tem plena identificação com o ato moral. Para ele (2000, p.61) "A consciência moral é o momento terminal que ratifica o ato como absolutamente singular; o ato do sujeito em sua inalienável identidade".

Segundo a ética vaziana, a consciência moral se caracteriza na vida ética em um vir-a-ser concreto por meio do qual o indivíduo se realiza eticamente. Em outras palavras, esse vir-a-ser caracterizado pela consciência moral se constitui cumulativamente, conduzindo o sujeito de modo progressivo e crescente ao seu fim, ao seu télos que é o Bem. Nesse sentido, Lima Vaz (1998, p.471) faz a seguinte afirmação:

A experiência da consciência moral mostra-a com evidência como elemento constitutivo do nosso agir moral. Ela é a expressão da sua estrutura reflexiva, na medida em que agir moralmente implica sempre como momento final da sua efetivação em ato o juízo e avaliação imanentes do teor moral do próprio ato. Nesse sentido a consciência moral pode ser considerada, em primeira aproximação, como sendo 
a componente reflexiva da posição final do agir na sua estrutura subjetiva, sendo o seu termo objetivo o fim por ele intencionado. Ela se delineia, pois, como a face reflexiva da síntese dos elementos e dos momentos que integram o exercício efetivo do agir ético.

Assim, a consciência moral vai aos poucos levando o agente ético a ter uma vida cada vez mais ética, mais voltada para o Bem, cada vez mais próxima da plenitude, da sua existência humana. Nesse sentido, esse aprofundamento contínuo conduz o agente ético a conquistar a sua ipseidade, aquilo que é ele mesmo, ou seja, aquilo que Lima Vaz denomina como personalidade moral. Dessa maneira, o ser humano torna-se aquilo que ele efetivamente é, ou seja, pessoa, de uma personalidade que, apesar de todas as condições adversas e fatores desfavoráveis, pode prosseguir na "peregrinação" ética de sua vida. Para ele, personalidade moral é "a forma da vida ética que assegura e orienta a continuidade dos atos que a constituem e, nesse sentido, é a forma da vida virtuosa". (LIMA VAZ, 2000, p.171)

Nesse sentido, vale ressaltar a observação de Elton Vitoriano (2015, p. 151) quando diz que existem autores que "dão significados diferentes aos termos ética e moral tentando exprimir aspectos diferentes da conduta humana. Assim, o aspecto individual estaria ligado a moral e o aspecto social estaria ligado a ética. Mas, etimologicamente, os termos ética e moral são sinônimos". Assim, podemos, pois, afirmar que a moral, a vida e o agir ético ocorrem não somente na realidade subjetiva, mas principalmente na intersubjetiva. Portanto, é na comunidade ética que o sujeito se depara com outro Eu. Portanto, é nesse contexto que a temática do nosso trabalho ocorre, pois é na face com o outro sujeito ético que o Consenso e Reconhecimento acontece.

\section{Consenso e Reconhecimento na Antropologia e na Ética Vaziana}

Em seu artigo Reconhecer-se reconhecido: o problema do reconhecimento enquanto questão antropológica, ética e política, Elton Vitoriano Ribeiro destaca que a gênese do conceito de reconhecimento se encontra na Fenomenologia do Espírito de He- 
gel, que tal como sabemos, muito inspirou a filosofia Vaziana. Para Ribeiro, Hegel, na dialética do senhor e escravo, afirma que a consciência-de-si do ser humano está relacionada à experiência do reconhecimento social. "No entanto, essa experiência acontece na forma de uma luta de vida e de morte entre o senhor e o escravo, por isso a afirmação amplamente conhecida de luta por reconhecimento" (RIBEIRO, 2016, p. 392). Importância tal que tem sido objeto de estudos de muitos filósofos contemporâneos tal como apresenta o estudo desse autor.

Para Lima Vaz, o sujeito ético é aquele que, dotado de razão e vontade e voltado para a Verdade e o Bem, se vê diante de situações particulares ao qual terá de escolher e aderir aquela que o conduzirá para o melhor, realizando assim um ato moral e consequentemente uma consciência e uma personalidade moral ao qual se identifica. No entanto, esse sujeito está inserido em uma comunidade com outros agentes morais que possuem essas mesmas características. Nesse sentido, tal como afirma Herrero (2012, p. 409) "o encontro com o outro como ato ético, exige, como primeira condição de possibilidade, o reconhecimento do horizonte comum de universalidade do Bem no qual o Eu acolhe o Outro como outro eu". Nesse mesmo sentido, Vaz afirma em sua obra Introdução a Ética Filosófica II que:

A universalidade da Razão prática desdobra-se em acolhimento do outro. Essa abertura de um novo espaço intencional significa que o agir ético, como ato próprio da Razão prática, não se encerra no interior da estrutura monódica do Eu, mas se autodetermina com relação essencial e constitutiva com outro Eu. Abre-se, assim, o campo para o exercício efetivo do agir ético, a saber, a comunidade ética que, por sua vez, realizar-se-á como comunidade histórica concreta na referência a um universo objetivo de bens, fins, normas e valores, ou seja, a um ethos historicamente realizado. (LIMA VAZ, 2000, p.71)

Nesse processo de reconhecimento do outro, um fator primordial, é a importância da linguagem que cumpre o papel de mediadora entre essas várias subjetividades. Para Lima Vaz, é através da linguagem gestual ou falada que os dois sujeitos, dotados de corpo, psique e espírito e aberto a relações, comunicar-se-ão, poderão formar a sua personalidade ética e consequentemente a comunidade ética. Nesse mesmo sentido, Martin Buber (1982, p.37) afirma que o diálogo "se comporta fora 
dos conteúdos comunicados e comunicáveis, mesmo os mais pessoais; (...) [se completa] num acontecimento que é concreto no sentido estrito da palavra, totalmente inserido no mundo comum aos homens e na sequência temporal concreta". Assim, Lima Vaz enfatiza a importância do diálogo para a formação da comunidade ética, onde para além dos signos, numa realidade concreta, os agentes éticos podem dialogar, comunicar e assim construir a comunidade ética visando a verdade e o bem, sendo assim pressuposto para o consenso, outra importante categoria da intersubjetividade ética que explanaremos a seguir.

Feito o reconhecimento e a aproximação por meio do diálogo, Lima Vaz insere em sua filosofia a categoria de Consenso, que tem a sua origem na relação intersubjetiva dos homens. Dessa maneira, esse autor faz a seguinte afirmação:

Uma vez reconhecido o outro no horizonte do Bem, a inclinação da vontade segue-se necessariamente ao reconhecimento para consentir na comunidade entre o eu e o Outro sob o signo da bondade. Por outro lado, sabemos que, do ponto de vista ético, a adesão da vontade ao Bem é, exatamente, a definição da liberdade. O consenso é um ato eminentemente livre e é como tal que pode ter lugar entre sujeitos éticos. (LIMA VAZ, 2000, p. 75)

Na ética Vaziana o consenso apresenta quatro níveis fundamentais: O primeiro é o nível do encontro, onde há a relação Eu-Tu pautada pela reciprocidade que traz consigo uma oblação, um dom-de-si embasado no amor e na fidelidade. Em seguida há o nível do consenso espontâneo, onde guiados pela amizade, os sujeitos colaboram espontaneamente e cordialmente nas tarefas da comunidade.

O terceiro nível é denominado por Vaz como consenso reflexivo "que se exprime na reciprocidade de direitos e deveres ou na forma da obrigação cívica" (LIMA VAZ, 2000, p. 77). Nessa etapa ocorre a passagem de uma sociedade convivial para uma sociedade política, em que a relação do Eu-nós se define pelas regras institucionais do consenso, ou seja, de uma lei do existir-comum, de uma constituição. Dessa maneira, "é nesse nível que se dá, por conseguinte, a necessária articulação entre Ética e Política" (LIMA VAZ, 2000, p. 77). Esse processo se desemboca em um outro nível que Vaz chama de comunica- 
ção intracultural, ao qual o homem "atinge a amplitude da relação Sub-humanidade na longa dimensão do tempo e do espaço onde se desenrola a História" (LIMA VAZ, 2000, p.79). Assim, o autor faz a seguinte afirmação:

Uma vez reconhecido o outro no horizonte do Bem, a inclinação da vontade segue-se necessariamente ao reconhecimento para consentir na comunidade entre o eu e o Outro sob o signo da bondade. Por outro lado, sabemos que, do ponto de vista ético, a adesão da vontade ao Bem é, exatamente, a definição da liberdade. O consenso é um ato eminentemente livre e é como tal que pode ter lugar entre sujeitos éticos. (LIMA VAZ, 2000, p. 75)

$\mathrm{Na}$ ética vaziana, consenso e reconhecimento estão associados à razão prática e se desenvolvem por meio de uma atividade volitiva. Em outras palavras, ele quer dizer que uma vez que o outro é reconhecido sob o horizonte do Bem, a vontade leva o agente ético a "consentir na comunidade entre o Eu e o Outro sob o signo da verdade" (LIMA VAZ, 2000, p.75). Quando essa vontade de reconhecer e consentir ocorre, há uma coesão do ethos, de modo que os indivíduos passam a se integrar uns aos outros.

Tendo em vista que ainda que reconhecimento e consenso sejam atos racionais, por dependerem, também, da vontade, faz necessário algumas ações da comunidade ética para que de fato se realizem nas relações intersubjetivas. Por isso que Lima Vaz aponta a importância de se oferecer uma "educação ética na qual as razões do ethos devem ser explicitadas e demonstradas" (LIMA VAZ, 2000, p.75), daí a importância de haver uma ciência do ethos ou uma disciplina intelectual do ethos que é a ética. Para Elton Vitoriano Ribeiro (2015, p.154)

Uma ética será uma totalidade estruturada que compreenderá princípios, valores e fins para a existência do ser humano. Ela será apreendida, primeiramente pela tradição e pelos indivíduos que a fazem viver, e posteriormente pela educação ética que se apresentará na forma de uma racionalidade filosófica, ou seja, na forma de um "discurso racionalmente ordenado das razões normativas, axiológicas e teleológicas presentes no mundo da vida".

Ademais, além dessa formação, Lima Vaz aponta que é importante que existam normas que ofereçam a passagem da 
subjetividade do indivíduo para uma validade objetiva possibilitada pela lei, que, por sua vez, tem caráter universal. Todavia, esse autor aponta que somente Leis não são suficientes para assegurar o reconhecimento e consenso, por isso a importância das instituições, que para ele, possuem uma grandeza social essencialmente normativa e tem a função de assegurar um quadro estável de exercício para ambos.

Nesse arcabouço, é de fundamental importância a categoria de justiça que vai fundamentar as ações das instituições e consequentemente das leis e por fim os meios de existência do reconhecimento e do consenso. Contudo, Lima Vaz tem a consciência de que não basta ter leis e instituições que garantam o reconhecimento e o consenso, fundamentos do agir e da vida ética em sua intersubjetividade, é necessário que essas sejam justas, virtuosas, ou seja, colaborem para que toda a comunidade ética caminhe em direção ao horizonte do Bem e da Verdade pois para ele (2000, p.178) “a justiça enquanto virtude é um hábito do indivíduo, enquanto lei é uma regulamentação permanente do agir dos indivíduos tendo em vista o bem da comunidade".

Lima Vaz, em sua lucidez, percebe que essa peregrinação rumo ao bem, reconhecimento e consenso é "continuamente ameaçada pela possibilidade do conflito" (OLIVEIRA, 2013, p.220). Assim, na particularidade, existem, tal como afirma Herrero (2012, p.412) "interesses de indivíduos ou grupos que surgem dentro do mesmo ethos no qual convivem". Há portanto uma série de condições e situações, sejam elas psicológicas, sociocultural, econômica, históricas, inseridas na malha do corpo da comunidade ética que a impedem de se realizar em sua plenitude. Por isso, a importância do reconhecimento para que o consenso possa efetivamente existir, pois o reconhecimento informa ao agente ético as condições situacionais dele e do outro, assegurando assim a eticidade da ação, e o consenso, por sua vez, leva o sujeito a consentir com outro tendo em vista o horizonte do bem naquela situação. Dessa maneira, reconhecimento aparece como causa formal e consenso como a causa eficiente do agir ético intersubjetivo. 
Tal movimento intercausal do reconhecimento e do consenso na particularidade das situações mostram o intento da ética de Lima Vaz em identificar e debruçar sobre os aspectos invariantes de uma ética inserida em contextos e situações tão diversas. Assim, independentemente das "dificuldades" que o agir e a vida ética intersubjetivos possam ter em seu caminhar para o Bem, há sempre um princípio fundamental ético que vai "ajudar" o sujeito ético a "voltar" ou "continuar" a sua intencionalidade para aquilo que é melhor, para o bem mais universal, pautado pelo diálogo. Dessa forma, independentemente das situações e conflitos, há na condição humana uma abertura que superará as possíveis divergências e que pautados pela Razão Prática, efetivadas pelo reconhecimento e consenso, nos mostra que ainda é possível seguir em busca do Bem, não em um contexto somente do "eu", mas também em um ambiente do "eu-tu" e do nós. Nesse processo, vai se formando, aquilo que Lima Vaz chama de consciência moral social dos participantes da comunidade ética, ou seja, uma comunidade que repousa sobre a realidade dos indivíduos que a partir do reconhecimento e consenso, tecem as relações sociais, constituindo um corpo, não somente de indivíduos isolados, mas um corpo comunitário.

A consciência moral social retoma, de certa forma, os tipos de níveis do existir-em-comum já citados na Antropologia Filosófica, tal como mencionamos acima, pois para Lima Vaz a consciência moral social pode se expressar no nível primordial Eu-tu, no nível comunitário do nós e no nível societário onde há a mediação das instituições, tal como os níveis do encontro, comunitário, reflexivo e intracultural da antropologia, acima descritos. Em cada um desses níveis se desenvolve a identidade da comunidade que busca o Bem e a Verdade através dos atos éticos dos sujeitos que a compõe por meio do reconhecimento e do consenso, que por sua vez, conforme vimos acima, só existe por causa a liberdade e da consciência moral individual que para Lima Vaz (2000, p.199) são "condições primeiras da abertura ao outro".

Por fim, Lima Vaz enfatiza que a categoria mais apta para exprimir a vida ética comunitária é a de dignidade. Quando o 
sujeito forma a sua personalidade moral, ele assume a sua dignidade, que tendo em vista que somos seres situados com outros seres situados e em constante relação, tal dignidade deve ser reconhecida por outros. Assim, Lima Vaz (2000, p.213) afirma que "somente o reconhecimento recíproco da dignidade entre os parceiros da relação do Nós como constitutiva da comunidade ética pode elevar essa relação ao nível da equidade e da igualdade: torna-la, em suma, uma relação de justiça"

Assim, Ética e Antropologia se encontram, pois ao mostrar a constituição do ser humano com aquele que ao constitui-se um ser de logos - se auto-expressa como Eu Sou e se percebe como dotado de corpo, psique e espirito e aberto à relação com o mundo, com o outro e com o Absoluto - percebe-se também como um ser ético, um ser de relação.

É nessa relação com o outro que o reconhecimento e o consenso se fazem necessários e fundamentais, para que então se construa uma consciência ética social e assim confirma aquilo que já era afirmado na Antropologia: o ser humano dotado de dignidade, uma pessoa ética, moral, aberta e em constante busca do Bem e da Verdade.

\section{Considerações finais}

Na primeira parte de nosso trabalho buscamos, ainda que de forma incipiente, apresentar as principais características da Antropologia de Lima Vaz. Verificamos que esse filósofo busca identificar o ser humano sobre duas vertentes: a dimensão estrutural e a dimensão relacional. No aspecto estrutural, Vaz identifica que o ser humano é primeiramente corpo, mas essa categoria é suprassumida pela categoria de psiquismo e tem o seu ápice na categoria de Espírito.

Ao mesmo tempo, o filósofo jesuíta afirma que o homem percebe-se também como um ser aberto para relações, por isso Lima Vaz se debruça sobre as categorias de objetividade, intersubjetividade e transcendência. Apresentamos, também, que a unidade desses aspectos do ser humano, do ser-para-si e do ser-para-outros, acontece através da categoria de realização onde 
o homem se torna ele mesmo na sua abertura constitutiva ao outro. Também verificamos que desse caminhar pela busca da percepção do homem sobre si mesmo, emerge a categoria de pessoa, síntese entre essência e existência, que é um caminho onde o homem continuamente busca realizar-se em sua humanidade mais radical.

Dada a categoria de pessoa, pudemos apresentar então a eticidade do ser humano e por isso nos debruçamos sobre a ética, ou seja, como convém viver. Dissemos, com Vaz, que a ética é regida pela Razão Prática que prescreve o Bem com télos do ser humano. Assim, através da liberdade e inteligência o homem adquire o hábito de buscar o bem em todo o seu agir e sua vida ética.

Mostramos que essa vida ética se dá com outros que também são regidos pela mesma Razão Prática, daí nasce o reconhecimento do outro como um ser ético que também busca o Bem e o Melhor em seu agir e em sua vida. Assim, ressaltamos que essa ideia do reconhecimento e do consenso já existia de forma seminal na Antropologia Filosófica quando Vaz afirma o ser humano aberto para o outro e o reconhece na comunidade ética e quando esse autor aborda os níveis fundamentais da relação de subjetividade, já pre-figurando o consenso que desenvolverá com mais profundidade na Ética Filosófica.

Assim como fizera na Antropologia, também buscamos apresentar a importância que Vaz oferece ao diálogo e à linguagem para a existência de uma comunidade ética aberta ao signo da verdade. Desta maneira, mostramos, também, que reconhecimento e consenso são assegurados na comunidade ética por meio de Leis e Normas pautadas pela justiça e que diante das condições e interferências existentes na particularidade da existência humana, buscarão sempre escolher aquilo que é melhor, que mais aproximar-se-á do bem. Desta maneira, forma-se uma consciência moral social que garanta a dignidade humana, reafirmando na ética aquilo que já estava presente na Antropologia: o homem como dotado de dignidade, uma pessoa ética, moral, aberta e em constante busca do Bem e da Verdade. 


\section{Referências}

BUBER, M. Do diálogo e do dialógico. São Paulo: Editora Perspectiva, 1982.

HERRERO, F. J. A Ética Filosófica de Henrique Cláudio de Lima Vaz. Síntese, Belo Horizonte, v. 39, n. 125, 2012

MACDOWELL, João, A. O pensamento de Padre Lima Vaz no contexto da filosofia contemporânea no Brasil. Revista Portuguesa de Filosofia, vol. 67, no. 2, 2011, pp. 231-253. Disponível em: www. jstor.org/stable/41803898. Acesso em: 3.maio. 2020.

JAPIASSÚ, Hilton e MARCONDES, Danilo. Dicionário Básico de Filosofia. 5.ed. Rio de Janeiro: Zahar, 2008

VAZ, H.C.L. Escritos de Filosofia V: Introdução à Ética Filosófica II. São Paulo: Loyola, 2000.

VAZ, H.C.L. Escritos de Filosofia IV. Antropologia Filosófica II. São Paulo: Loyola, 1992.

VAZ, H.C.L. Escritos de Filosofia III: Filosofia e Cultura. São Paulo: Loyola, 1997.

VAZ, H.C.L. Crise e verdade da consciência moral. Síntese, Belo Horizonte, v. 25 n. 83, 1998.

OLIVEIRA, C. M. Metafísica e ética: a filosofia da pessoa em Lima Vaz como resposta ao niilismo contemporâneo. São Paulo: Loyola, 2013.

OLIVEIRA, C. CARDOSO, D. Ação ética intersubjetiva na ética Filosófica de Lima Vaz. Síntese, Belo Horizonte, v. 35, n. 113, 2008

RIBEIRO, Elton Vitoriano. A ética filosófica de Padre H. C. Lima Vaz, SJ. Brasiliensis - Revista do Centro de Estudos Filosóficos - Teológicos Redemptoris Mater, v. 4, p. 147-172, 2015

RIBEIRO, Elton Vitoriano. Reconhecer-se reconhecido: o problema do reconhecimento enquanto questão antropológica, ética e política. Síntese, Belo Horizonte, v.43,n.137,p.387-400, Set./Dez.,2016. 